\title{
Reporting quality of practice guidelines on colorectal cancer: evaluation using the RIGHT reporting checklist
}

\author{
Jing Han ${ }^{1 \#}$, Meng Tao ${ }^{2 \#}$, Xuan $\mathrm{Wu}^{1}$, Ding $\mathrm{Li}^{3}$, Yanfang $\mathrm{Ma}^{4}$, Shaheenah Dawood ${ }^{5}$, Colin W. Steele ${ }^{6}$, \\ Ker-Kan Tan ${ }^{7}$, Qiming Wang ${ }^{1}$
}

${ }^{1}$ Department of Internal Medicine, Affiliated Cancer Hospital of Zhengzhou University, Henan Cancer Hospital, Zhengzhou, China; ${ }^{2}$ Department of General Surgery, Huaihe Hospital of Henan University, Kaifeng, China; ${ }^{3}$ Department of Pharmacy, Henan Cancer Hospital Affiliated to Zhengzhou University, Zhengzhou, China; ${ }^{4}$ School of Chinese Medicine of Hong Kong Baptist University, Kowloon Tong, Hong Kong, China; ${ }^{5}$ Department of Medical Oncology, Mediclinic City Hospital - North Wing, Mohammed Bin Rashid University of Medicine and Health Sciences, Dubai Health Care City, Dubai, United Arab Emirates; ${ }^{6}$ University Department of Surgery, Glasgow Royal Infirmary, Glasgow, UK; ${ }^{7}$ Division of Colorectal Surgery, University Surgical Cluster, National University Health System, Singapore, Singapore

Contributions: (I) Conception and design: Q Wang, Y Ma, J Han; (II) Administrative support: X Wu, D Li; (III) Provision of study materials or patients: J Han, M Tao; (IV) Collection and assembly of data: J Han, M Tao, X Wu; (V) Data analysis and interpretation: J Han, M Tao; (VI) Manuscript writing: All authors; (VII) Final approval of manuscript: All authors.

"These authors contributed equally to this work.

Correspondence to: Qiming Wang, MD, PhD. Department of Internal Medicine, Affiliated Cancer Hospital of Zhengzhou University, Henan Cancer Hospital, 127 Dong Ming Road, Zhengzhou 450008, China. Email: qimingwang1006@126.com.

Background: Clinical practice guidelines are an essential tool for translating evidence into practice. Reporting Items for Practice Guidelines in Healthcare (RIGHT) checklist assists to guide the reporting in guidelines. We used RIGHT to assess the reporting completeness and quality of guidelines on colorectal cancer (CRC).

Methods: We searched the electronic databases Medline (via PubMed), Chinese National Knowledge Infrastructure (CNKI), Wanfang and Chinese Biomedical Literature (CBM) from January 1st, 2018 to December 1st, 2020 for guidelines on CRC. Websites of guideline development organizations were also searched. Two investigators assessed the reporting quality of the included guidelines, and calculated the numbers of guidelines that were compliant with each RIGHT checklist item and the mean proportions of reported items for each of the seven RIGHT checklist domains.

Results: Twenty-seven colorectal guidelines were included. The proportions of reported items in each RIGHT domain were $71.0 \%$ for Basic information, $66.2 \%$ for Background, $45.9 \%$ for Evidence, $68.8 \%$ for Recommendations, $24.1 \%$ for Review and quality assurance, 33.3\% for Funding and declaration and management of interests, and $40.7 \%$ for Other information.

Conclusions: The reporting quality of colorectal guidelines was moderate. A systematic use of the RIGHT checklist during the development process could improve the reporting quality of guidelines in the future.

Keywords: Colorectal cancer (CRC); clinical practice guideline; reporting quality; Reporting Items for Practice Guidelines in Healthcare (RIGHT)

Submitted Mar 16, 2021. Accepted for publication Jul 02, 2021.

doi: 10.21037/atm-21-2798

View this article at: https://dx.doi.org/10.21037/atm-21-2798 


\section{Introduction}

Colorectal cancer (cancer of the colon or rectum, or bowel cancer, CRC) is the third most common malignancy in terms of incidence, and the fourth leading cause of cancerrelated death worldwide (1). About 1.85 million new cases of CRC occurred and 881,000 people died from CRC worldwide in 2018 (2). The incidence of CRC has increased in recent years as modern lifestyle factors known to be associated with the risk of CRC (such as certain dietary and lifestyle changes, obesity, sedentary behavior, and alcohol and tobacco use) have become more widespread, which represents a significant burden to the society (3). In 2016, the global burden of CRC was estimated at 17.2 million disability-adjusted life years. Notably, $97 \%$ of the disease burden resulted from years of life lost due to premature mortality (4). An increasing number of countries have thus become more concerned about CRC, developing a diversity of clinical practice guidelines for screening, diagnosis and treatment of CRC to optimize patient care. High-quality guidelines can effectively enhance decision-making by clinicians and patients by translating complex scientific research findings into concise recommendations, improving the quality and reducing the cost of medical services (5). However, the reporting quality of CRC guidelines has not yet been systematically and comprehensively evaluated.

The International Reporting Items for Practice Guidelines in Healthcare (RIGHT) checklist was developed and launched by a multidisciplinary international working group in 2016 (6). The RIGHT tool contains an explanation and elaboration statement with detailed information and examples, which the AGREE (Appraisal of Guidelines for Research and Evaluation) reporting tool, an early instrument for reporting quality assessment of guidelines, lacks (6). In practice, RIGHT checklist can assist guideline developers in reporting, journal editors and peer reviewers in decision making, and health care practitioners in understanding and implementing guidelines $(3,6,7)$.

Therefore, we used the RIGHT checklist to evaluate the reporting quality of guidelines on screening, detection, diagnosis, treatment and management of CRC published between 2018 and 2020. Our aim was to identify reporting deficiencies reporting in guidelines in this field, and provide suggestions for the development of guidelines in the future. In addition to guidelines published in English, we included guidelines from China as an example of guidelines with a focus on country-specific recommendations, and compared the reporting quality of guidelines from China with that of the rest of the world.

\section{Methods}

\section{Literature search}

We searched the databases Medline (via PubMed), Chinese National Knowledge Infrastructure (CNKI), Wanfang and Chinese Biomedical Literature (CBM) from January 1st, 2018 to December 1st, 2020 to identify guidelines on CRC. We also searched the websites of the following guideline development and oncology organizations: the World Health Organization (WHO), National Institute for Health and Care Excellence (NICE), Guidelines International Network (GIN), National Comprehensive Cancer Network (NCCN), Scottish Intercollegiate Guidelines Network (SIGN), and Chinese Society of Clinical Oncology (CSCO). We used the following search strategy: ("Guideline" OR "Recommendation") AND [“"colorectal*” OR "colon*” OR "rect" OR "intestine ${ }^{*}$ ") AND ("Cancer*" OR "carcinoma*" OR "neoplasm*" OR "adenoma*" OR "adenocarcinom*" OR "tumour*" OR "tumor*" OR "polyp*" OR "malignan")], adjusted to the format of each database. The search strategies for different databases are presented in detail in the Supplementary Appendix 1.

\section{Eligibility criteria and study selection}

We included all evidence-based guidelines on CRC published between January 1, 2018 to December 1, 2020 in English or Chinese in either peer-reviewed journals or on publicly available websites. We excluded translations, summaries and interpretations of guidelines, as well as older versions of guidelines if an updated edition was available.

Two investigators (Jing Han and Xuan Wu) independently screened first the retrieved titles and abstracts, and then the full texts of the articles deemed potentially eligible, and selected eligible studies according to the predefined criteria. Disagreements were resolved by consensus or by consultation with a senior investigator (Meng Tao).

\section{Data collection}

One investigator extracted the following information from the included guidelines: title, publication year, country or region of development, developer, grading system, and the journal or website where the guideline was published. If some of these data could not be retrieved, we contacted the 
authors of the articles to ask for the missing information. Quality assessment was performed independently by two trained investigators (Jing Han and Xuan $\mathrm{Wu}$ ), who reviewed the quality of each eligible guideline. Conflicting opinions or disagreements were solved by consulting a third investigator (Meng Tao).

\section{RIGHT checklist}

The RIGHT tool provides evaluators a clear, transparent and comprehensive checklist with accompanying explanations and detailed instructions. It contains 35 items grouped into seven domains: basic information, background, evidence, recommendations, review and quality assurance, funding and declaration and management of interests, and other information. Before collecting the data, the researchers attended a training course on the use of the RIGHT checklist to ensure that the evaluation criteria were applied consistently. Most items were evaluated on a dichotomous scale ("Fully Reported" or "Not Reported"). "Fully Reported" means that relevant information was fully reported, and "not reported" that the relevant information was completely missing. If an item did not apply to the guideline, we assigned it as "Not applicable". For items with multiple contents [for example, "If the guideline developers used existing systematic reviews, reference these and describe how those reviews were identified and assessed (provide the search strategies and the selection criteria, and describe how the risk of bias was evaluated) and whether they were updated"], we added a third possible answer, "Partially Reported", meaning that a part of the content was reported.

\section{Data analysis}

We calculated the percentages of guidelines that were compliant with each of the 35 RIGHT items, as well as the overall reporting rates (the sum of all items assigned as either "Fully Reported" or "Partially Reported" divided by the total number of items) and the mean reporting rates for each of the RIGHT checklist domains (reporting rate of items within each domain) for all guidelines. We presented the mean reporting rates over all guidelines, and for guidelines stratified by continent. We calculated the mean differences (MD) with $95 \%$ confidence intervals (CI) comparing the overall and domain reporting rates between guidelines from China and the rest of the world, as well as between guidelines published in peer-reviewed journals and on websites only. $\mathrm{T}$ tests were used to test statistical significance. The analyses were conducted with SPSS 24.0 and Review Manager 5.3.

\section{Results}

Our search identified a total of 1,015 records, of which 932 remained after removing duplicates. After screening the titles and abstracts, 870 articles were excluded. Finally, 27 guidelines were deemed eligible in the full-text review and included in the analysis (Figure 1).

\section{Characteristics of the included guidelines}

Nine $(33.3 \%)$ guidelines were developed in the United States (USA) and published mainly by American Cancer Society (ACS), American Society of Clinical Oncology (ASCO) and National Comprehensive Cancer Network (NCCN), 6 (22.2\%) by European multinational organizations or collaborations, and four (14.8\%) in China. The remaining guidelines were from France $(n=2)$, Spain $(\mathrm{n}=2)$, United Kingdom $(\mathrm{n}=1)$, Japan $(\mathrm{n}=1)$, Italy $(\mathrm{n}=1)$ and Canada $(n=1)$ developed by their independent domestic research institutions. Six (22.2\%) guidelines were published only on the website of the developer. Twenty-two guidelines $(81.5 \%)$ performed grading of evidence quality and recommendation strength, of which eleven guidelines used the GRADE system (Table 1).

\section{Overall reporting quality of included guidelines}

The overall reporting rates of the RIGHT items in the 27 guidelines ranged from $22.9 \%$ to $85.7 \%$, with a mean of $56.3 \%$. Ten guidelines $(37.0 \%$ ) had a score above $60 \%$, 15 guidelines $(55.6 \%)$ between $30 \%$ and $60 \%$, and two guidelines (7.4\%) lower than $30 \%$ (Table 2).

\section{Reporting quality of each domain}

The mean reporting quality in the "Basic information" domain was highest (71.0\%), and the reporting quality in the domain "Review and quality assurance" the lowest (24.1\%) among the seven RIGHT domains. The mean reporting proportions in the remaining domains were 68.8\% (Recommendations), 66.2\% (Background), 45.9\% (Evidence), $40.7 \%$ (Other information), and $33.3 \%$ (Funding and declaration and management of interests) (Table 2). 


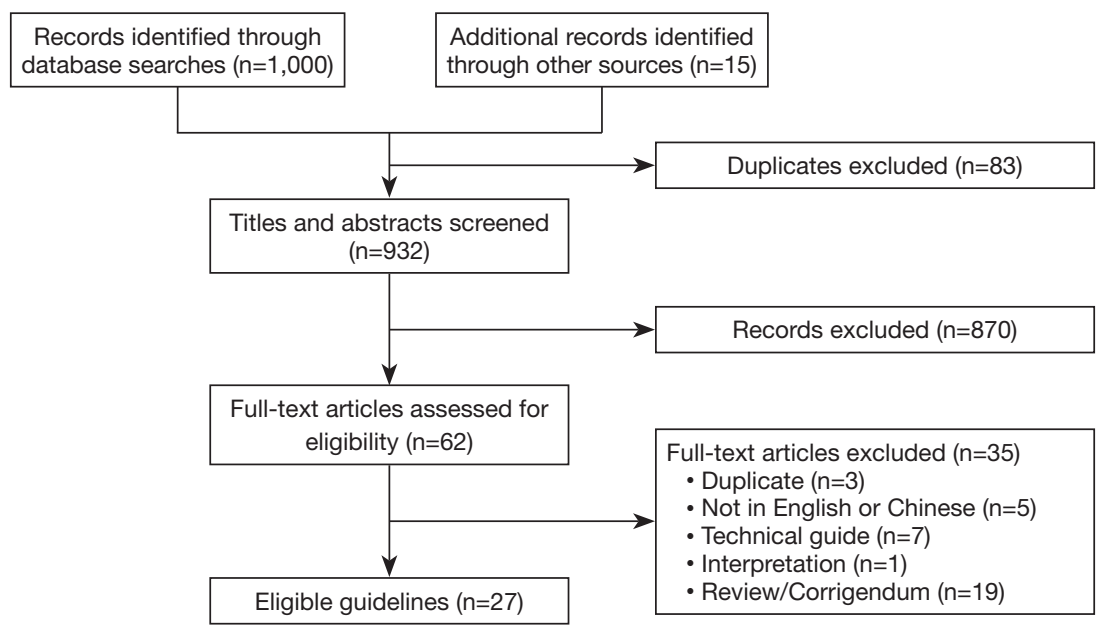

Figure 1 Flowchart of the literature search.

\section{Reporting quality of each item}

Items $7 \mathrm{a}$ [Describe the primary population(s) that is addressed by the recommendation(s) in the guideline] and 13 a (Provide clear, precise, and actionable recommendations) of the RIGHT checklist was reported in all guidelines. No guideline reported item $18 \mathrm{~b}$ [Describe the role of funder(s) in the different stages of guideline development and in the dissemination and implementation of the recommendations]. Sixteen sub-items (1b, 2, 8b, 9a, 10a, 10b, 11b, 14a, 15, 16,17, $18 \mathrm{~b}, 19 \mathrm{~b}, 21,22)$ were reported by less than half of the guidelines (Figure 2).

The reporting rates of guidelines developed in different continents varied across the seven domains of the RIGHT checklist. For "Basic information", the guidelines developed in Asia had the highest reporting proportion $(83.3 \%)$. For the other domains of RIGHT checklist, North America guidelines had the highest reporting rate (Figure 3). The guidelines from rest of the world had slightly higher reporting quality than those from China ( $\mathrm{MD}=0.26,95 \% \mathrm{CI}:-0.04$ to $0.57, \mathrm{P}=0.082$ ); the difference was significant in the domains "Evidence" $(\mathrm{P}<0.00001)$, "Recommendations" $(\mathrm{P}<0.00001)$ and "Other information" ( $\mathrm{P}=0.0002)$ (Figure 4). The reporting quality of guidelines did also not differ significantly between those published in peer-reviewed journals and those published on websites only (MD $=0.09,95 \% \mathrm{CI}:-0.03$ to 0.20 , $\mathrm{P}=0.136$ ). Guidelines published in journals had a higher reporting rate in the "Basic information" domain than guidelines published on websites only (Figure 5).

\section{Discussion}

We reviewed 27 guidelines on CRC to evaluate their reporting quality, and found that the mean compliance to the items of the RIGHT checklist was $56.3 \%$. The reporting rates of items related to the review and quality assurance and funding and declaration and management of interest were lower than of items related to other aspects. The reporting quality of guidelines on CRC is thus suboptimal and needs improvement.

More than half of the guidelines did not provide a summary of the recommendations. Guidelines developers may not fully understand the importance of providing a summary: previous study found that the low reporting rate in the "basic information" domain resulted from the insufficient importance attached by guideline developers (35). Another possible reason is that most journals do not have a specific submission category for guidelines, so when a guideline is published in a journal it needs to fit the standard article format which usually does not contain sections such as a summary of the recommendations. A complete executive summary is however essential as it presents the key points such as the target population and recommendations of the guideline in a concise format, assisting the readers find the key information directly and quickly. Otherwise, guideline users need to read through the full document to find the recommendations relevant to the problem of concern. Most CRC guidelines also did not report the target country or setting that their guideline. Because of the incomplete reporting healthcare practitioners or clinicians may find it 


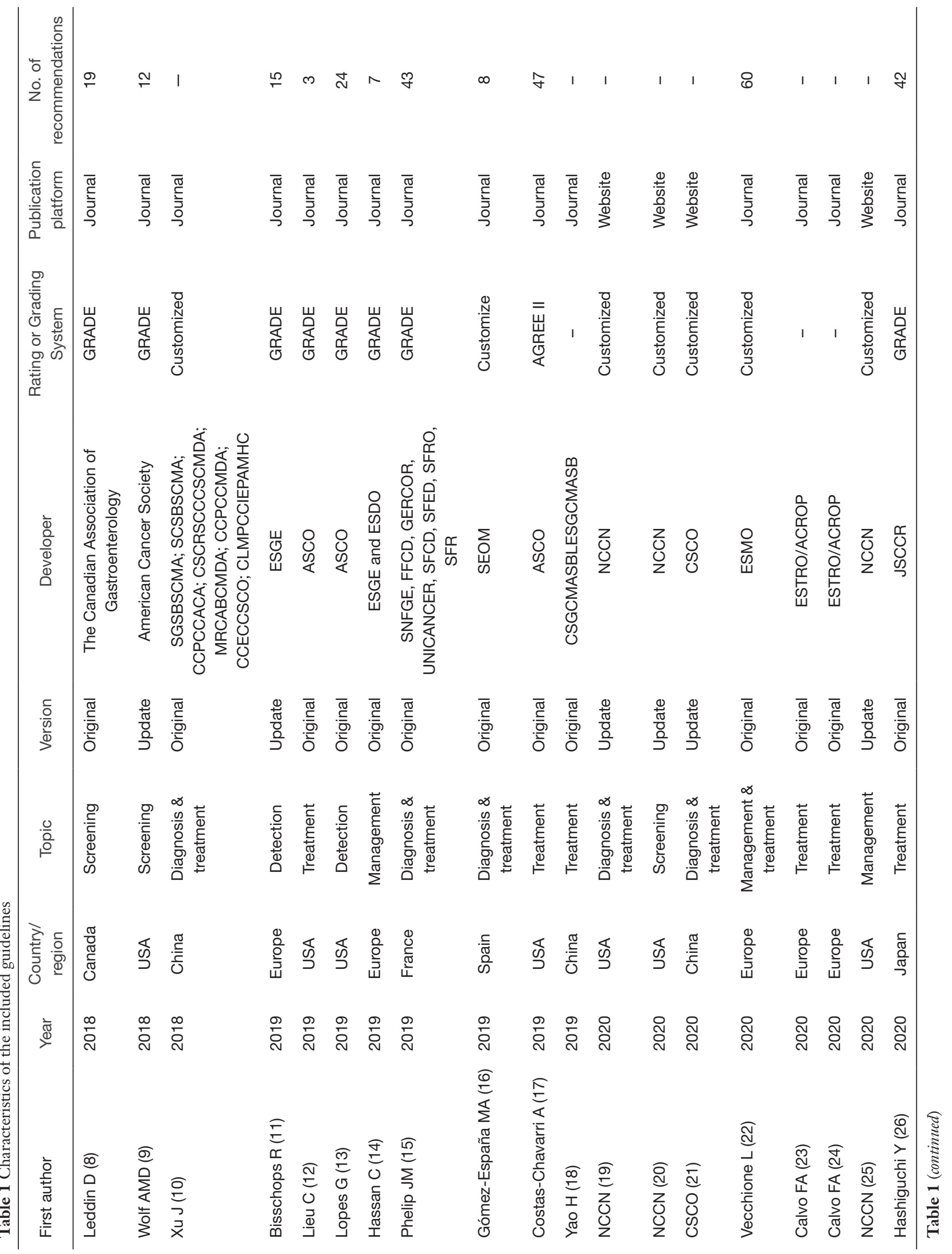




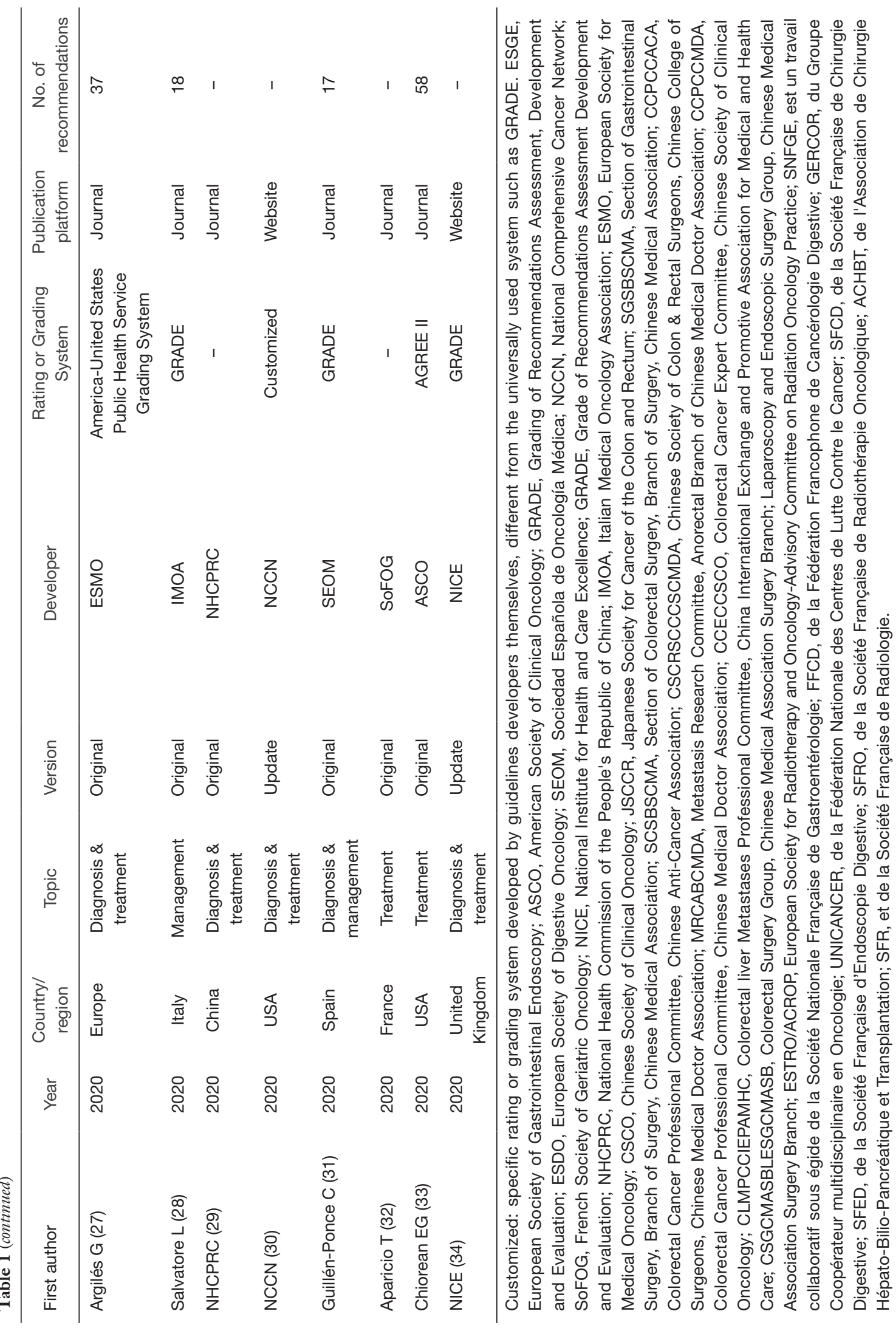


Table 2 Compliance to each item of RIGHT in the included guidelines(6)

\begin{tabular}{|c|c|c|c|c|c|}
\hline No. & Item & $\begin{array}{l}\text { Fully reported, } \\
\text { n (\%) }\end{array}$ & $\begin{array}{l}\text { Partially } \\
\text { reported, } \mathrm{n}(\%)\end{array}$ & $\begin{array}{l}\text { Not reported, } \\
\mathrm{n}(\%)\end{array}$ & $\begin{array}{l}\text { Not applicable, } \\
\text { n (\%) }\end{array}$ \\
\hline \multicolumn{6}{|c|}{ Basic information } \\
\hline 1a & $\begin{array}{l}\text { Identify the report as a guideline, that is, with } \\
\text { "guideline(s)" or "recommendation(s)" in the title }\end{array}$ & $26(96.3)$ & $0(0.0)$ & $1(3.7)$ & $0(0.0)$ \\
\hline $1 b$ & Describe the year of publication of the guideline & $13(48.1)$ & $0(0.0)$ & $14(51.9)$ & $0(0.0)$ \\
\hline 2 & $\begin{array}{l}\text { Provide a summary of the recommendations contained } \\
\text { in the guideline }\end{array}$ & $12(44.4)$ & $0(0.0)$ & $15(55.6)$ & $0(0.0)$ \\
\hline 3 & $\begin{array}{l}\text { Define new or key terms, and provide a list of } \\
\text { abbreviations and acronyms if applicable }\end{array}$ & $26(96.3)$ & $1(3.7)$ & $0(0.0)$ & $0(0.0)$ \\
\hline \multicolumn{6}{|c|}{ Background } \\
\hline 5 & $\begin{array}{l}\text { Describe the basic epidemiology of the problem, such } \\
\text { as the prevalence/incidence, morbidity, mortality, and } \\
\text { burden (including financial) resulting from the problem }\end{array}$ & $23(85.2)$ & $0(0.0)$ & $4(14.8)$ & $0(0.0)$ \\
\hline 6 & $\begin{array}{l}\text { Describe the aim(s) of the guideline and specific } \\
\text { objectives, such as improvements in health indicators } \\
\text { (e.g., mortality and disease prevalence), quality of life, or } \\
\text { cost savings }\end{array}$ & $16(59.3)$ & $0(0.0)$ & $11(40.7)$ & $0(0.0)$ \\
\hline $7 a$ & $\begin{array}{l}\text { Describe the primary population(s) that is addressed by } \\
\text { the recommendation(s) in the guideline }\end{array}$ & $27(100.0)$ & $0(0.0)$ & $0(0.0)$ & $0(0.0)$ \\
\hline $8 b$ & $\begin{array}{l}\text { Describe the setting(s) for which the guideline is } \\
\text { intended, such as primary care, low- and middle-income } \\
\text { countries, or in-patient facilities }\end{array}$ & $4(14.8)$ & $0(0.0)$ & $23(85.2)$ & $0(0.0)$ \\
\hline $9 a$ & $\begin{array}{l}\text { Describe how all contributors to the guideline } \\
\text { development were selected and their roles and } \\
\text { responsibilities (e.g., steering group, guideline panel, } \\
\text { external reviewer, systematic review team, and } \\
\text { methodologists) }\end{array}$ & $11(40.7)$ & $0(0.0)$ & $16(59.3)$ & $0(0.0)$ \\
\hline $9 b$ & $\begin{array}{l}\text { List all individuals involved in developing the guideline, } \\
\text { including their title, role(s) and institutional affiliation(s) }\end{array}$ & 24 (88.9) & $0(0.0)$ & $3(11.1)$ & $0(0.0)$ \\
\hline \multicolumn{6}{|c|}{ Evidence } \\
\hline $10 a$ & $\begin{array}{l}\text { State the key questions that were the basis for the } \\
\text { recommendations in PICO (population, intervention, } \\
\text { comparator, and outcome) or other format as } \\
\text { appropriate }\end{array}$ & $10(37.0)$ & $0(0.0)$ & $17(63.0)$ & $0(0.0)$ \\
\hline
\end{tabular}

Table 2 (continued) 
Table 2 (continued)

\begin{tabular}{|c|c|c|c|c|c|}
\hline No. & Item & $\begin{array}{l}\text { Fully reported, } \\
\qquad \mathrm{n}(\%)\end{array}$ & $\begin{array}{l}\text { Partially } \\
\text { reported, } \mathrm{n}(\%)\end{array}$ & $\begin{array}{l}\text { Not reported, } \\
\mathrm{n}(\%)\end{array}$ & $\begin{array}{l}\text { Not applicable, } \\
\text { n (\%) }\end{array}$ \\
\hline $10 \mathrm{~b}$ & Indicate how the outcomes were selected and sorted & $3(11.1)$ & $0(0.0)$ & $24(88.9)$ & $0(0.0)$ \\
\hline $11 a$ & $\begin{array}{l}\text { Indicate whether the guideline is based on new } \\
\text { systematic reviews done specifically for this guideline or } \\
\text { whether existing systematic reviews were used }\end{array}$ & $21(77.8)$ & $0(0.0)$ & $6(22.2)$ & $0(0.0)$ \\
\hline 12 & $\begin{array}{l}\text { Describe the approach used to assess the certainty of } \\
\text { the body of evidence }\end{array}$ & $20(74.1)$ & $0(0.0)$ & $7(25.9)$ & $0(0.0)$ \\
\hline $13 a$ & Provide clear, precise, and actionable recommendations & $27(100.0)$ & $0(0.0)$ & $0(0.0)$ & $0(0.0)$ \\
\hline $13 b$ & $\begin{array}{l}\text { Present separate recommendations for important } \\
\text { subgroups if the evidence suggests that there } \\
\text { are important differences in factors influencing } \\
\text { recommendations, particularly the balance of benefits } \\
\text { and harms across subgroups }\end{array}$ & $23(85.2)$ & $0(0.0)$ & $0(0.0)$ & $4(14.8)$ \\
\hline $13 c$ & $\begin{array}{l}\text { Indicate the strength of recommendations and the } \\
\text { certainty of the supporting evidence }\end{array}$ & $19(70.4)$ & $4(14.8)$ & $0(0.0)$ & $4(14.8)$ \\
\hline $14 a$ & $\begin{array}{l}\text { Describe whether values and preferences of the target } \\
\text { population(s) were considered in the formulation of } \\
\text { each recommendation. If yes, describe the approaches } \\
\text { and methods used to elicit or identify these values } \\
\text { and preferences. If values and preferences were not } \\
\text { considered, provide an explanation }\end{array}$ & $10(37.0)$ & $0(0.0)$ & $17(63.0)$ & $0(0.0)$ \\
\hline $14 c$ & $\begin{array}{l}\text { Describe other factors taken into consideration when } \\
\text { formulating the recommendations, such as equity, } \\
\text { feasibility and acceptability }\end{array}$ & $16(59.3)$ & $0(0.0)$ & $11(40.7)$ & $0(0.0)$ \\
\hline 15 & $\begin{array}{l}\text { Describe the processes and approaches used by } \\
\text { the guideline development group to make decisions, } \\
\text { particularly the formulation of recommendations (such } \\
\text { as how consensus was defined and achieved and } \\
\text { whether voting was used) }\end{array}$ & $12(44.4)$ & $0(0.0)$ & $15(55.6)$ & $0(0.0)$ \\
\hline
\end{tabular}

Table 2 (continued) 
Table 2 (continued)

\begin{tabular}{|c|c|c|c|c|c|}
\hline No. & Item & $\begin{array}{l}\text { Fully reported, } \\
\qquad \mathrm{n}(\%)\end{array}$ & $\begin{array}{l}\text { Partially } \\
\text { reported, } \mathrm{n}(\%)\end{array}$ & $\begin{array}{l}\text { Not reported, } \\
\mathrm{n}(\%)\end{array}$ & $\begin{array}{l}\text { Not applicable, } \\
\text { n (\%) }\end{array}$ \\
\hline \multicolumn{6}{|c|}{ Review and quality assurance } \\
\hline \multicolumn{6}{|c|}{ Funding and declaration and management of interests } \\
\hline $18 \mathrm{a}$ & $\begin{array}{l}\text { Describe the specific sources of funding for all stages of } \\
\text { guideline development }\end{array}$ & $0(0.0)$ & $16(59.3)$ & $11(40.7)$ & $0(0.0)$ \\
\hline $18 b$ & $\begin{array}{l}\text { Describe the role of funder(s) in the different stages of } \\
\text { guideline development and in the dissemination and } \\
\text { implementation of the recommendations }\end{array}$ & $0(0.0)$ & $0(0.0)$ & $16(59.3)$ & $11(40.7)$ \\
\hline $19 b$ & $\begin{array}{l}\text { Describe how conflicts of interest were evaluated and } \\
\text { managed and how users of the guideline can access the } \\
\text { declarations }\end{array}$ & $6(22.2)$ & $0(0.0)$ & $21(77.8)$ & $0(0.0)$ \\
\hline \multicolumn{6}{|c|}{ Other information } \\
\hline 20 & $\begin{array}{l}\text { Describe where the guideline, its appendices, and other } \\
\text { related documents can be accessed }\end{array}$ & $18(66.7)$ & $0(0.0)$ & $9(33.3)$ & $0(0.0)$ \\
\hline 21 & $\begin{array}{l}\text { Describe the gaps in the evidence and/or provide } \\
\text { suggestions for future research }\end{array}$ & $11(40.7)$ & $0(0.0)$ & $16(59.3)$ & $0(0.0)$ \\
\hline
\end{tabular}

The details of RIGHT checklist can be found at http://www.right-statement.org/right-statement/checklist.

difficult to know if and when the guideline is applicable.

Although most guidelines reported the approach and to assess the certainty of the evidence and strength of the recommendations, we identified some guidelines that did not report any method to assess this information. In the era of evidence-based medicine, the development of guidelines and the formation of recommendations should follow standardized procedures. Clear and transparent assessment of the strength of recommendations and the quality of evidence can help clinical practitioners and clinicians to make explicit decisions for specific subpopulations or conditions.

Our comparison between guidelines from China and elsewhere found that guidelines from China had a lower reporting quality in reporting the evidence, review and quality assurance, funding and declaration and management of interests than guidelines from the rest of the world. It is possible that guideline from China developers do not attach enough attention in describing the development process. This finding is supported by another study showing that the adherence of guidelines from China to the RIGHT checklist was poor, below 30\% (36). Many users rely on the guidelines developed by a panel of experts in the field who have rich experience in clinical practice but little knowledge about standard guideline procedures in China (37). Thus, many guidelines lack transparency in searching, evaluating and composing evidences to have a poor quality. However, a scientific and standardized process can benefit further 


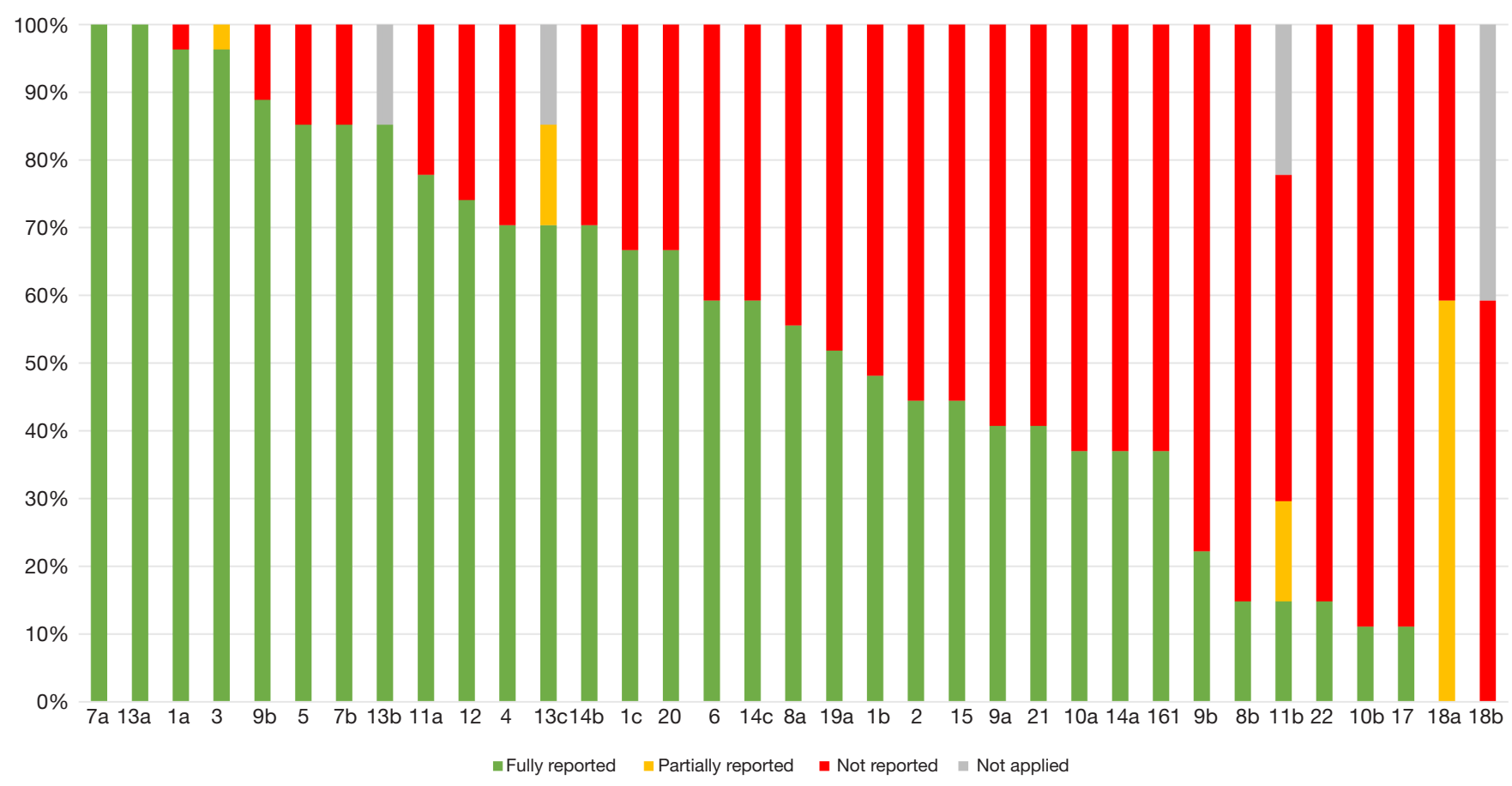

Figure 2 Percentage distribution of the scores for each item of the RIGHT checklist ( $\mathrm{n}=27)$. The descriptions of each item can be found in Table 2. RIGHT, Reporting Items for Practice Guidelines in Healthcare.

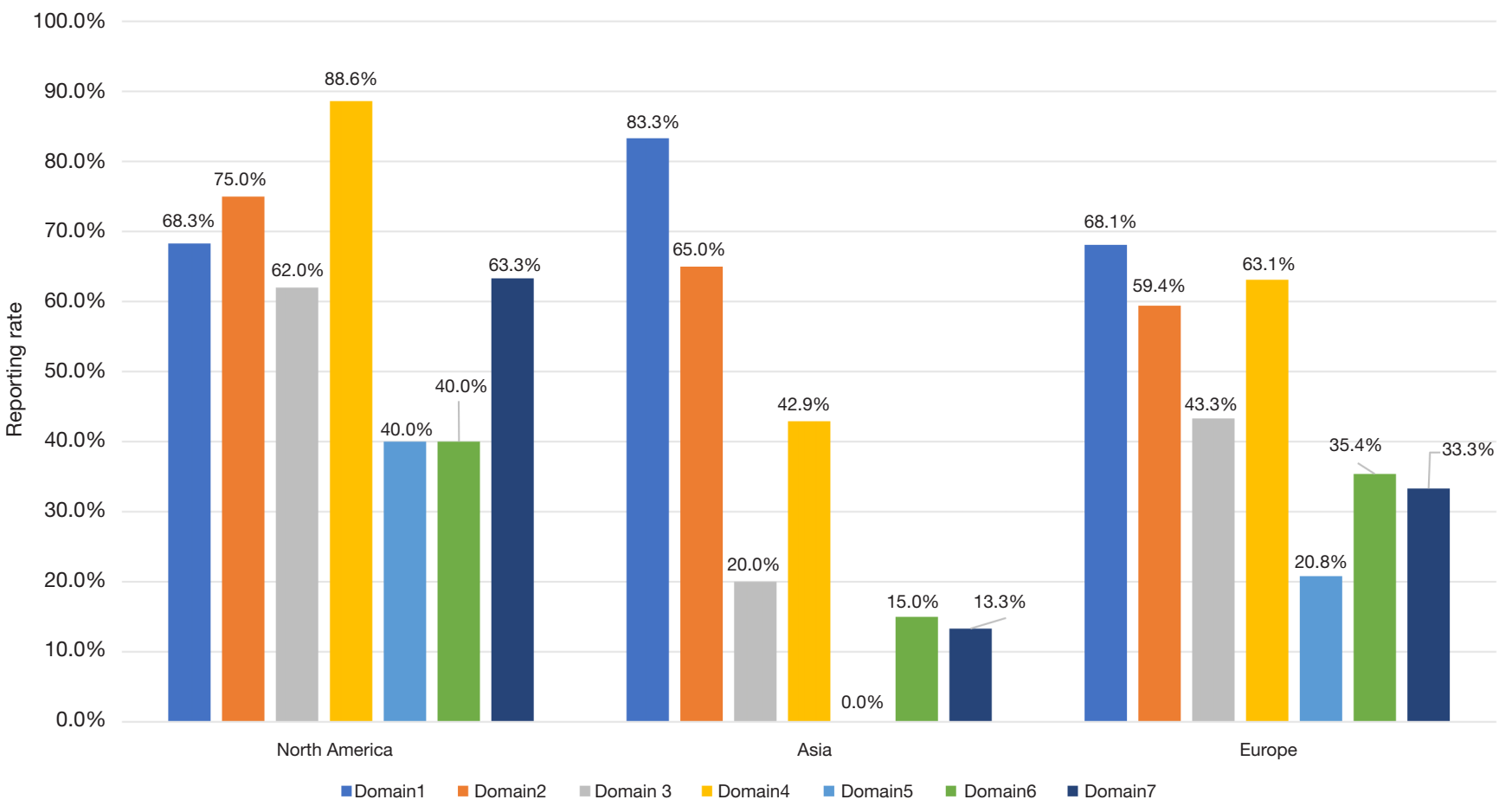

Figure 3 Comparison of reporting quality in each domain of the RIGHT checklist between guidelines developed in different continents. RIGHT, Reporting Items for Practice Guidelines in Healthcare. 


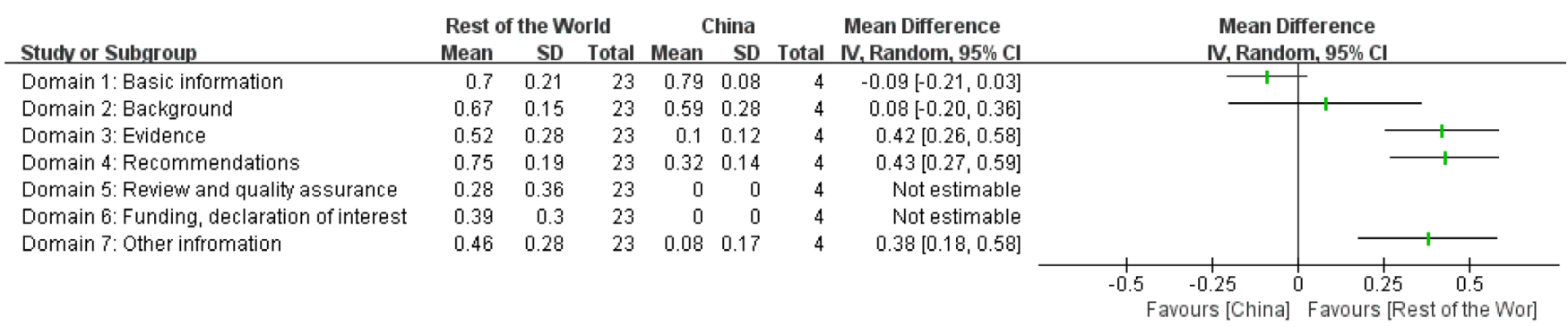

Figure 4 Comparison of reporting quality in each domain of the RIGHT checklist between guidelines developed in China and rest of the world. SD, standard deviation; CI, confidence interval; RIGHT, Reporting Items for Practice Guidelines in Healthcare.

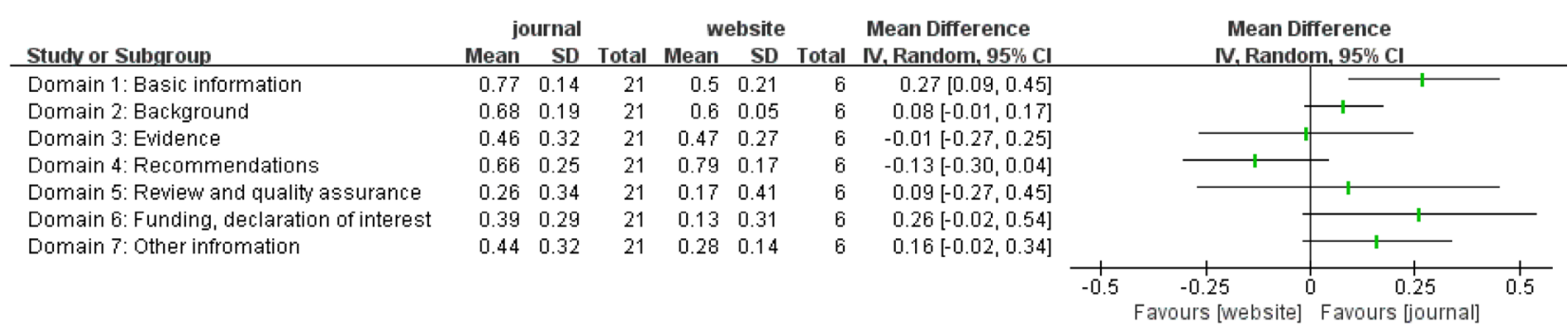

Figure 5 Comparison of reporting quality in each domain of the RIGHT checklist between guidelines published in journals and on websites only. SD, standard deviation; CI, confidence interval; RIGHT, Reporting Items for Practice Guidelines in Healthcare.

acceptance and dissemination of the guidelines, so Chinese developers should pay more attention on presenting the details of the development thoroughly to make up for the present deficiency in the future. Moreover, Asians are different in heredity, body constitution and other aspects with the west, so Asian specific guidelines need to be developed standardly according to RIGHT checklist to provide better guidance to the public.

We found that guidelines published on websites had the trend to report the evidence and recommendations better than those published in journals. In other domains, guidelines in journals tended to be better reported than those published on websites only. Many aspects in these domains such as funding and declaration and management of interests are standard requirements of journal article submissions. Two thirds of the website guidelines we included were NCCN guidelines which are well recognized in the field of oncology, but they nevertheless showed low reporting rates on these areas. Although NCCN guidelines play a significant role in the diagnosis and treatment of CRC to clinicians throughout the world, the reporting rates are inadequate in some domains, and improvements in reporting should be considered.
What is worth mentioning is that the reporting rate of funding, declaration and management of interest seems poor, the second lowest of RIGHT checklist domains in our study. Actually, this problem has existed many years all over the world. When guideline recommendations are controversial, and that's often, suspicion quickly turns to financial conflicts of interest. The perception of conflicts can call the reliability of a recommendation into question, and even more so if there was no disclosure (38). So developers should attach enough significance to the transparency of disclosure of financial interest. Specifically, clinical guidelines should describe the funding sources and roles of funders for all stages clearly and how conflicts of interest were evaluated and managed and how users of the guideline can access the declarations. Only with adequate financial conflict management, can guidelines become acceptable to a far wider circle.

Multiple tools, including AGREE, have been developed to assess the quality and reliability of guidelines and recommendations (39-41). The RIGHT checklist was developed to primarily give guidance during the actual guideline development process and support clear and transparent reporting, but it also completes the existing 
tools in assessing reporting quality. RIGHT is an evolving document that is being continuously revised and extended for different types of guidelines, in the future also possibly using the users' feedback (6). As we found the reporting in many aspects incompliant with the RIGHT checklist items, we anticipate that promoting the consistent use of RIGHT during the guideline development process could considerably improve the quality of guidelines in the future.

\section{Strengths and limitations}

To the best of our knowledge, this is the first study to apply the RIGHT checklist to assess the reporting quality for CRC guidelines. We performed critical quality control in the evaluation process, by two investigators conducting the assessment independently followed by a thorough and systematic discussion on any unclear or conflicting opinions. However, the present study has some limitations. We only include guidelines published in English or Chinese, meaning that our findings are not necessarily representative of the situation of CRC guidelines with a more national or local focus.

\section{Questions to be further discussed and considered}

Question 1: What impact do you think the low reporting quality of clinical practice guidelines on colorectal cancer will have on clinicians and clinical practices?

\section{Expert opinion: Dr. Shabeenab Dawood}

Personally I don't think it will have a major impact on actual care of patients in clinical practice since most clinicians use high quality guidelines such as the NCCN and ESMO. However it can cause confusion when multiple low quality guidelines are published. It thus becomes the responsibility of journals publishing to ensure that submitted guidelines adhere rigorous quality parameters and it becomes also important for authors to be transparent about reporting quality guidelines followed.

\section{Expert opinion: Dr. Colin W. Steele}

Clinical guidelines should address the evidence for them, reflected by grades of evidence with clear descriptions of how this was assessed within the guideline. These guidelines should be developed by experts to ensure the most robust and contemporaneous evidence is included. Low reporting quality of certain guidelines may unfavorably promote practices that do not have the strongest evidence base alongside those that do, leading to poorer quality patient care and irregular practices.

\section{Expert opinion: Dr. Ker-Kan Tan}

I think 2 issues. Some oncologists and surgeons may have pre-conceived ideas that clinical practice guidelines are inaccurate and biased. And hence, they would continue to do what they have been doing without the backing of the latest evidence. This would then translate to direct implications on patients' oncological outcomes as well as counselling of the associated risks and complications of each treatment options.

Question 2: What do you think the most important aspects needed for developing high-quality clinical practice guidelines on colorectal cancer are?

\section{Expert opinion: Dr. Shaheenab Dawood}

Need to group together established experts in the field.

(I) Need to include upcoming experts in the field who are not biased and the contribute appropriately.

(II) Experts should include those who are geographic specific to the guidelines as well as those from an international perspective.

(III) Adhering to the right check list is important.

(IV) Surveying the impression of the guidelines within the community it is targeting prior to publication may also be something think about to get feed back from community oncologist.

\section{Expert opinion: Dr. Colin W. Steele}

Clinical practice guidelines should be developed by an international collaborative. A thorough systematic literature search should be performed and data extracted from high quality meta-analysis and randomized controlled trial sources. The guidelines must cover all aspects of the clinical experience and remain contemporaneous. Guidance should be easily accessed and summarized with easy to follow instruction.

\section{Expert opinion: Dr. Ker-Kan Tan}

To develop high quality CPG in this current field of literature is difficult because of the plethora of open access publications citing their own evidence, whilst also the everpresence of publication biases and this is complicated by the appointments of certain "famous" clinicians to review the evidence and therefore to come up with the CPGs.

Firstly, the wide-ranging of predatory journals and widely available open access publications often confuse patients, clinicians and academics alike on what are the most robust evidence.

Secondly, only publications with statistically significant results are published due to publication biases. Rarely are 
well-conducted and large scale surgical trials performed, and even if they do, issues of sample size, heterogeneity and surgical expertise are huge confounders.

Lastly, we often only appoint esteemed clinicians to review the evidence to come up with the CPG who may have fixated ideas. CPGs should involve academics looking at modelling, health economics other than just clinicians in that particular field, say, colorectal cancer.

Question 3: How do you think conflicts of interest in the guidelines should be handled?

\section{Expert opinion: Dr. Shabeenab Dawood}

This is a very important question as conflict of interest can introduce biases on multiple levels. First authors should be bound to reveal all conflict of interest no matter how insignificant. Failure to declare should carry a hefty penalty. Second journals should investigate thoroughly conflicts that could potentially introduce biases e.g., having stocks in a company that the author is a PI on or having a spouse working in a company for which the author is leading and reporting on clinical trials or authors that have a large chunk of their publications and research focused on a specific drug etc. Here not is only is transparency important but it is vital that such authors not be the lead authors of such guidelines as this can be interpreted as bias. Not only is declaration of conflict interest important but the amount of renumeration obtained should also be declared privately to the journals to decide the level of conflict that could be detrimental.

\section{Expert opinion: Dr. Colin W. Steele}

Conflicts of interest should be stated upfront in an open and clear fashion. Conflicts of interest should be removed from the guidance by having a panel of experts from different areas of colorectal cancer management sitting together to discuss any controversies and come to a consensus as to how to proceed. Those with conflict over certain areas of the guidelines should be excluded from discussions around these parts to try and minimize inherent bias. There should be sufficient depth of this grouping to prevent biased guidelines being proposed. By presenting the quality and depth of evidence for a certain approach any conflict of interest should be overcome.

\section{Expert opinion: Dr. Ker-Kan Tan}

Conflict of interest is often understated and is subconscious. Although upfront declaration is mandatory, that does not mean that subsequent decisions would not have conflict of interest. Clarity of intent of the guidelines associated with the methodology would be critical to minimise individual's influence.

\section{Conclusions}

Our critical assessment of CRC guidelines found that they were of moderate reporting quality. The reporting of evidence basis, review and quality assurance, and funding and declaration and management of interests were particularly worrying. In the future, guideline developers should pay particular attention on reporting these aspects of the guidelines. The RIGHT checklist is a useful tool to assist guideline developers to report their guidelines clearly and transparently.

\section{Acknowledgments}

The authors appreciate the academic support from the AME Reporting Guideline Collaborative Group.

Funding: This work was supported by a project cosponsored by the Henan Province Health and Youth Subject Leader Training Project (No. [2020]60) and in part by the Leading Talent Cultivation Project of Henan Health Science and Technology Innovation Talents (No. YXKC2020009). It was also supported by the Huilan Charity Fund (No. HL-HS2020-129). The funders had no role in the study design, data collection and analysis, decision to publish, or preparation of the manuscript.

\section{Footnote}

Conflicts of Interest: All authors have completed the ICMJE uniform disclosure form (available at https://dx.doi. org/10.21037/atm-21-2798). The authors have no conflicts of interest to declare.

Ethical Statement: The authors are accountable for all aspects of the work in ensuring that questions related to the accuracy or integrity of any part of the work are appropriately investigated and resolved.

Open Access Statement: This is an Open Access article distributed in accordance with the Creative Commons Attribution-NonCommercial-NoDerivs 4.0 International License (CC BY-NC-ND 4.0), which permits the noncommercial replication and distribution of the article with the strict proviso that no changes or edits are made and the original work is properly cited (including links to both the formal publication through the relevant DOI and the license). 


\section{Page 14 of 15}

See: https://creativecommons.org/licenses/by-nc-nd/4.0/.

\section{References}

1. Kuipers EJ, Grady WM, Lieberman D, et al. Colorectal cancer. Nat Rev Dis Primers 2015;1:15065.

2. Bray F, Ferlay J, Soerjomataram I, et al. Global cancer statistics 2018: GLOBOCAN estimates of incidence and mortality worldwide for 36 cancers in 185 countries. CA Cancer J Clin 2018;68:394-424.

3. Rawla P, Sunkara T, Barsouk A. Epidemiology of colorectal cancer: incidence, mortality, survival, and risk factors. Prz Gastroenterol 2019;14:89-103.

4. WHO. World Cancer Report: Cancer Research for Cancer Prevention. 2020. Available online: https://www. iarc.fr/featured-news/new-world-cancer-report/

5. Graham R, Mancher M, Miller Wolman D, et al., editors. Clinical Practice Guidelines We Can Trust. Washington, DC: The National Academies Press, 2011.

6. Chen Y, Yang K, Marušic A, et al. A Reporting Tool for Practice Guidelines in Health Care: The RIGHT Statement. Ann Intern Med 2017;166:128-32.

7. Schulz KF, Altman DG, Moher D, et al. CONSORT 2010 Statement: updated guidelines for reporting parallel group randomised trials. BMC Med 2010;8:18.

8. Leddin D, Lieberman DA, Tse F, et al. Clinical Practice Guideline on Screening for Colorectal Cancer in Individuals With a Family History of Nonhereditary Colorectal Cancer or Adenoma: The Canadian Association of Gastroenterology Banff Consensus. Gastroenterology 2018;155:1325-1347.e3.

9. Wolf AMD, Fontham ETH, Church TR, et al. Colorectal cancer screening for average-risk adults: 2018 guideline update from the American Cancer Society. CA Cancer J Clin 2018;68:250-81.

10. $\mathrm{XuJ}$, Ren L. China Guideline for Diagnosis and Comprehensive Treatment of Colorectal Liver Metastases (Version 2018). Zhonghua Wei Chang Wai Ke Za Zhi 2018;21:601-26.

11. Bisschops R, East JE, Hassan C, et al. Advanced imaging for detection and differentiation of colorectal neoplasia: European Society of Gastrointestinal Endoscopy (ESGE) Guideline - Update 2019. Endoscopy 2019;51:1155-79.

12. Lieu C, Kennedy EB, Bergsland E, et al. Duration of Oxaliplatin-Containing Adjuvant Therapy for Stage III Colon Cancer: ASCO Clinical Practice Guideline. J Clin Oncol 2019;37:1436-47.

13. Lopes G, Stern MC, Temin S, et al. Early Detection for
Han et al. RIGHT evaluation for colorectal cancer guidelines

Colorectal Cancer: ASCO Resource-Stratified Guideline. J Glob Oncol 2019;5:1-22.

14. Hassan C, Wysocki PT, Fuccio L, et al. Endoscopic surveillance after surgical or endoscopic resection for colorectal cancer: European Society of Gastrointestinal Endoscopy (ESGE) and European Society of Digestive Oncology (ESDO) Guideline. Endoscopy 2019;51:C1.

15. Phelip JM, Tougeron D, Léonard D, et al. Metastatic colorectal cancer (mCRC): French intergroup clinical practice guidelines for diagnosis, treatments and followup (SNFGE, FFCD, GERCOR, UNICANCER, SFCD, SFED, SFRO, SFR). Dig Liver Dis 2019;51:1357-63.

16. Gómez-España MA, Gallego J, González-Flores E, et al. SEOM clinical guidelines for diagnosis and treatment of metastatic colorectal cancer (2018). Clin Transl Oncol 2019;21:46-54.

17. Costas-Chavarri A, Nandakumar G, Temin S, et al. Treatment of Patients With Early-Stage Colorectal Cancer: ASCO Resource-Stratified Guideline. J Glob Oncol 2019;5:1-19.

18. Yao H, Zhang Z, Zheng M. Chinese expert consensus and clinical practice guidelines for transanal total mesorectal excision of rectal cancer (Version 2019). Chinese Journal of Practical Surgery 2019;39:1121-8.

19. NCCN. Colon Cancer Version 4. 2020. Available online: www.ncen.org

20. NCCN. Colorectal Cancer Screening Version 2. 2020. Available online: www.nccn.org NCCN.

21. Guidelines of Chinese Society of Clinical Oncology (CSCO). Colorectal Cancer (Version 2020). Available online: www.csco.org.cn

22. Vecchione L, Stintzing S, Pentheroudakis G, et al. ESMO management and treatment adapted recommendations in the COVID-19 era: colorectal cancer. ESMO Open 2020;5:e000826.

23. Calvo FA, Sole CV, Rutten HJ, et al. ESTRO/ACROP IORT recommendations for intraoperative radiation therapy in locally recurrent rectal cancer. Clin Transl Radiat Oncol 2020;24:41-8.

24. Calvo FA, Sole CV, Rutten HJ, et al. ESTRO/ACROP IORT recommendations for intraoperative radiation therapy in primary locally advanced rectal cancer. Clin Transl Radiat Oncol 2020;25:29-36.

25. NCCN. Genetic/Familial High-Risk Assessment: Colorectal-2020.v1. 2020. Available online: www.nccn.org

26. Hashiguchi Y, Muro K, Saito Y, et al. Japanese Society for Cancer of the Colon and Rectum (JSCCR) guidelines 2019 for the treatment of colorectal cancer. Int J Clin Oncol 
2020;25:1-42.

27. Argilés G, Tabernero J, Labianca R, et al. Localised colon cancer: ESMO Clinical Practice Guidelines for diagnosis, treatment and follow-up. Ann Oncol 2020;31:1291-305.

28. Salvatore L, Imperatori M, Arnoldi E, et al. Management of patients with early-stage colon cancer: guidelines of the Italian Medical Oncology Association. ESMO Open 2020;5:e001001.

29. National Health Commission Of The People's Republic Of C. National guidelines for diagnosis and treatment of colorectal cancer 2020 in China (English version). Chin J Cancer Res 2020;32:415-45.

30. NCCN. Genetic/Familial High-Risk Assessment: Colorectal Version 1. 2020. Available online: www.nccn.org

31. Guillén-Ponce C, Lastra E, Lorenzo-Lorenzo I, et al. SEOM clinical guideline on hereditary colorectal cancer (2019). Clin Transl Oncol 2020;22:201-12.

32. Aparicio T, Canouï-Poitrine F, Caillet P, et al. Treatment guidelines of metastatic colorectal cancer in older patients from the French Society of Geriatric Oncology (SoFOG). Dig Liver Dis 2020;52:493-505.

33. Chiorean EG, Nandakumar G, Fadelu T, et al. Treatment of Patients With Late-Stage Colorectal Cancer: ASCO Resource-Stratified Guideline. JCO Glob Oncol 2020;6:414-38.

Cite this article as: Han J, Tao M, Wu X, Li D, Ma Y, Dawood S, Steele CW, Tan KK, Wang Q. Reporting quality of practice guidelines on colorectal cancer: evaluation using the RIGHT reporting checklist. Ann Transl Med 2021;9(14):1175. doi: $10.21037 /$ atm-21-2798
34. NICE. Colorectal cancer. 2020. Available online: www. nice.org.uk/guidance/ng151

35. Zhao Y, Li Y, Li J, et al. Reporting quality of chronic kidney disease practice guidelines according to the RIGHT statement: a systematic analysis. Ther Adv Chronic Dis 2020;11:2040622320922017.

36. Wang Q, Duan Y, Liang J, et al. Reporting quality of 20142018 clinical practice guidelines on diabetes according to the RIGHT checklist. Endocrine 2019;65:531-41.

37. Yang K, Chen Y, Li Y, et al. Editorial: can China master the guideline challenge? Health Res Policy Syst 2013;11:1.

38. Bastian H. Nondisclosure of Financial Interest in Clinical Practice Guideline Development: An Intractable Problem? PLoS Med 2016;13:e1002030.

39. Brouwers MC, Kho ME, Browman GP, et al. AGREE II: advancing guideline development, reporting, and evaluation in health care. Prev Med 2010;51:421-4.

40. Schünemann HJ, Wiercioch W, Etxeandia I, et al. Guidelines 2.0: systematic development of a comprehensive checklist for a successful guideline enterprise. CMAJ 2014;186:E123-42.

41. Grimmer K, Dizon JM, Milanese S, et al. Efficient clinical evaluation of guideline quality: development and testing of a new tool. BMC Med Res Methodol 2014;14:63. 


\section{Supplementary}

\section{PubMed search strategy}

\#1 colorectal Neoplasms [MeSH]

\#2 Cancer* OR carcinoma* OR neoplasm* OR adenoma* OR adenocarcinom* OR tumour* OR tumor* OR polyp* OR malignan* [Title/Abstract]

\#3 Colorectal* OR colon* OR rect* OR intestine* [Title/ Abstract]

\#4 \#2 AND \#3

\#5 \#1 OR \#4

\#6 Guideline [Publication Type]

\#7 Practice Guideline [Publication Type]

\#8 guideline*[Title]

\#9 guidance*[Title]

\#10 recommendation*[Title]

\#11 OR /\#6-\#10

\#12 \#5 AND \#11

\section{CBM search strategy}

\#1 “结肠”[常用字段:智能]

\#2 “直肠”[常用字段:智能]

\#3 “结直肠”[常用字段:智能]

\#4 “大肠”[常用字段:智能]

\#5 “肠”[常用字段:智能]

\#6 OR \#1- \#5

\#7 “癌”[常用字段:智能]

\#8 “肿瘤”[常用字段:智能]

\#9 \#7 or \#8

\#10 \#6 AND \#9

\#11 “结肠肿瘤”[不加权:扩展]

\#12 “乙状结肠肿瘤”[不加权:扩展]

\#13 \#11 OR \#12

\#14 \#10 OR \#13

\#15 “指南”[常用字段:智能]

\#16 “推荐意见”[常用字段:智能]

\#17 “指南”[不加权:扩展]

\#18 OR \#15-\#17

\#19 \#14 AND \#18

\section{Wanfang search strategy}

\#1 主题:结肠

\#2 主题:直肠

\#3 主题:大肠

\#4 主题:结直肠

\#5 主题:肠

\#6 OR \#1- \#5

$\# 7$ 主题:癌

\#8 主题:肿瘤

\#9 \#7 or \#8

\#10 题名:(指南 or 推荐意见)

\#11 (\#6 AND \#9) AND \#10

\section{CNKI search strategy}

$\# 1$ 主题:结肠癌

\#2 主题:直肠癌

\#3 主题:大肠癌

\#4 主题:结直肠癌

\#5 主题:肠肿瘤

\#6 OR \#1- \#5

\#7 题名:指南

\#8 题名:推荐意见

\#9 \#7 or \#8

\#10 \#6 AND \#9 